\title{
Use of dried blood for measurement of trans fatty acids Ruby Gupta ${ }^{1}$, Ransi Ann Abraham ${ }^{1}$, Savita Dhatwalia ${ }^{1}$, Lakshmy Ramakrishnan*1, Dorairaj Prabhakaran² and Kolli Srinath Reddy ${ }^{3}$
}

\author{
Address: ${ }^{1}$ Department of Cardiac Biochemistry, All India Institute of Medical Sciences, Ansari Nagar, New Delhi-110029, India, ${ }^{2}$ Center for \\ Chronic Disease Control, Safdarjung Development Area, New Delhi-110016, India and 3Public Health Foundation of India, New Delhi-110016, \\ India \\ Email: Ruby Gupta - g_ruby2123@yahoo.co.in; Ransi Ann Abraham - ransijob@gmail.com; Savita Dhatwalia - cardiacbiochem@gmail.com; \\ Lakshmy Ramakrishnan* - lakshmy_ram@yahoo.com; Dorairaj Prabhakaran - dprabhakaran@ccdcindia.org; \\ Kolli Srinath Reddy - ksreddy@ccdcindia.org \\ * Corresponding author
}

Published: 24 July 2009

Nutrition Journal 2009, 8:35 doi:10.1 186/1475-289/-8-35

This article is available from: http://www.nutritionj.com/content/8/I/35

(C) 2009 Gupta et al; licensee BioMed Central Ltd.

This is an Open Access article distributed under the terms of the Creative Commons Attribution License (http://creativecommons.org/licenses/by/2.0), which permits unrestricted use, distribution, and reproduction in any medium, provided the original work is properly cited.
Received: 13 March 2009

Accepted: 24 July 2009

\begin{abstract}
Background: Fatty acid measurements especially trans fatty acid has gained interest in recent times. Among the various available biomarkers, adipose tissue is considered to be the best for the long term dietary intake but the invasive nature of tissue aspiration reduces its utility. Phlebotomy is a much less invasive method of sample collection when a large number of participants are involved in the study and therefore is an alternative, most suitable for large population based studies. In the present study fatty acid (with special emphasis on trans fatty acid) extraction from blood spotted and dried on filter paper was carried out to simplify the sample collection procedure and transportation.
\end{abstract}

Methods: Blood samples were collected from 19 healthy volunteers. The blood was spotted (30 spots of $10 \mu \mathrm{leach}$ ) on filter paper, dried at room temperature and stored at $4^{\circ} \mathrm{C}$ in zip-lock poly bags. For comparison whole blood stored at $-70^{\circ} \mathrm{C}$ was simultaneously analyzed.

Results: A good agreement was seen between trans fatty acid values obtained in dried blood and whole blood as evident from the pearson correlation coefficients (' $r$ ' for monounsaturated (trans) 0.70 and for polyunsaturated (trans) 0.692 respectively). The intraclass correlation coefficient for monounsaturated trans was 0.805 and for polyunsarurated trans was 0.776 .

Conclusion: Dried blood spots can be used for trans fatty acid analysis.

\section{Background}

Fatty acid measurement in adipose tissue, whole blood, erythrocyte membrane, serum or plasma, and specific plasma fractions serve as biomarkers of exogenously consumed fatty acids [1,2]. The different biomarkers reflect intake over several hours to past few years. Adipose tissue is considered to be the best biomarker for the long term dietary intake [3] because of its slow turnover but the invasive nature of tissue aspiration reduces its utility. Whole blood as a biomarker of fatty acid assessment is amenable to widespread usage in epidemiological studies due to the relative ease of collection, processing and storage compared to other biomarkers. Fasting whole blood has been reported to be a suitable biomarker, with performance comparable to that of fasting plasma [4]. 
Measurement of trans fatty acids intake is of interest due to adverse health implications [5-7]. A suitable biomarker for trans fatty acid which is relatively less invasive and easy to transport would be useful in epidemiological studies where a central laboratory is responsible for analysis from blood collected from far off areas. Blood samples collected in the field needs to be stored at very low temperatures and transported in dry ice for measurement of fatty acids. A method that circumvents the need for blood processing, storage and shipment of samples at very low temperatures would therefore be desirable and dried blood is a promising alternative. The filter paper matrix stabilizes most analytes in dried blood spots, but the rate of sample degradation will vary from analyte to analyte and storage conditions. In the present study we explored the possibility of blood collected on filter paper and stored at $4^{\circ} \mathrm{C}$ for measurement of fatty acids including trans fatty acids.

\section{Method}

Fasting blood samples were collected from 19 volunteers who were apparently healthy. Written consent was obtained from all volunteers. $5 \mathrm{ml}$ of blood was collected in vacuum tubes with EDTA as additive. Replicates of blood spots (30 spots of $10 \mu$ l each) were prepared by dropping blood on Whatman filter paper (no. 3) kept on a non absorbent surface and allowed to dry at room temperature, transferred to a zip-lock poly bag and stored in a refrigerator $\left(2-8^{\circ} \mathrm{C}\right)$ for fifteen days. Whole blood was stored at $-70^{\circ} \mathrm{C}$ till the time of analysis. Fatty acids were analyzed in both the dried blood and the corresponding whole blood samples. For fatty acid analysis in dried blood, ten punches of dried blood spot of $6 \mathrm{~mm}$ size each were taken in culture tubes with Teflon caps. $200 \mu$ l saline was added to extract blood from the filter paper. For whole blood fatty acid estimation $200 \mu \mathrm{l}$ whole blood was directly used for fat extraction. $1800 \mu \mathrm{l}$ of isopropanol/ chloroform $(11: 7, \mathrm{v} / \mathrm{v})$ containing $50 \mathrm{mg}$ of 2,6-di-tertbutyl-p-cresol as an antioxidant was added to the extract from dried blood and whole blood samples [8]. The tubes were left at room temperature for an hour with intermittent shaking. The lower chloroform layer was aspirated and dried under nitrogen. Esterification was done using method of Leepage \& Roy [9] with modification. $500 \mu \mathrm{l}$ methanol-acetyl chloride 20:1 (v/v) was added to the tubes and heated in water-bath at $100^{\circ} \mathrm{C}$ for 1 hour. $3 \mathrm{ml}$ of cold potassium carbonate was added to each tube slowly with continuous shaking. Methyl esters were extracted with $200 \mu$ l hexane. The solvent was evaporated under the stream of nitrogen and esters were re-dissolved in iso-octane. $1 \mu \mathrm{l}$ sample was loaded on fused silica capillary cis/trans column SP 2560, $100 \mathrm{~m} \times 250 \mu \mathrm{m}$ internal diameters $\times 0.20 \mu \mathrm{m}$ film (Supelco, Belefonte, Pennsylvania). The port temperatures of both the injector and the detector were set at $250^{\circ} \mathrm{C}$. The oven temperature was ini- tially set at $90^{\circ} \mathrm{C}$ for $4 \mathrm{~min}$ and was then increased $15^{\circ} \mathrm{C} /$ min until a temperature of $150^{\circ} \mathrm{C}$ was reached and held for $10 \mathrm{~min}$, the temperature was further increased at $1^{\circ} \mathrm{C} /$ min till $170^{\circ} \mathrm{C}$ after which rate of temperature change was $5^{\circ} \mathrm{C} / \mathrm{min}$ until a temperature of $230^{\circ} \mathrm{C}$ was reached and maintained for 30 minutes. The total run time was 80 min. A split ratio of $1: 10$ and an injection volume of $1 \mu \mathrm{l}$ were used. The Gas Chromatograph was equipped with Flame - ionization detector using Nitrogen as carrier gas. Sample fatty acid methyl ester peaks were identified by comparing their retention times with those of known standards (Fatty Acid Methyl Esters from SUPELCO). Each peak was quantified by calculating the area under the peak using software from AIMIL (Nucon Technologies). The concentration of individual fatty acid was expressed as percentage of total area under the peaks.

Extraction and methylation for whole blood and their spots were performed in pairs to avoid within pair variability. C 17:0 was used as an internal standard. All reagents used were of HPLC grade. Known standards of fatty acids: a mixture of 37 components (C4-C24), and individual trans fatty acid methyl esters: Palmitelaidic acid methyl ester (C 16:1,7t), Elaidic acid methyl ester (C18:1, 9t), Vaccenic acid methyl ester (C18:1, 11t), Linoleic acid methyl ester isomer mix ( $\mathrm{C} 18: 2,9,12-\mathrm{tt}, \mathrm{tc}$, $\mathrm{ct}$ \& $\mathrm{cc}$ ) were run for identifying peak retention time of individual fatty acids in unknown samples. Monounsaturated, polyunsaturated, saturated and trans fatty acids (MUFA and PUFA) total were recalculated from the sums of fatty acids detected in each category. The fatty acids included among total saturated fatty acids are C 12:0,C 14:0,C 16:0 and C 18.0 , and those in total monounsaturated (cis) are $\mathrm{C} 14: 1$ cis, C 16:1 cis and C 18:1 cis. Total PUFA (cis) includes C 18:2 cis, cis, C 18:3 n-6, C 18:3 n-3 and C 20:4 n-6. Total MUFA (trans) comprises of C 16:1 7-trans, C 18:1 9-trans and $\mathrm{C}$ 18:1 11-trans. The total PUFA (trans) included $\mathrm{C}$ 18:2 trans, trans, C 18:2 trans, cis and C 18:2 cis, trans.

Pearson correlation and Intraclass correlations were calculated to determine correlation between values obtained with dried blood and whole blood. Data analysis was done with SPSS software package.

\section{Results}

Coefficient of variation for measurement of fatty acids when same sample was run in triplicates was $1.05 \%$ for saturated fatty acid, $0.77 \%$ for mono unsaturated fatty acid, $1.03 \%$ for poly unsaturated fatty acid and 6.55 for total trans fatty acid. For Inter day precision, same sample was run on six different days and the coefficient of variation for saturated fatty acid was $1.52 \%$, for monounsaturated it was $1.55 \%$, for polyunsaturated it was $0.66 \%$ and for total trans it was $13.25 \%$. Figure $1 \&$ Figure 2 shows the correlation between fatty acids in individual whole blood 

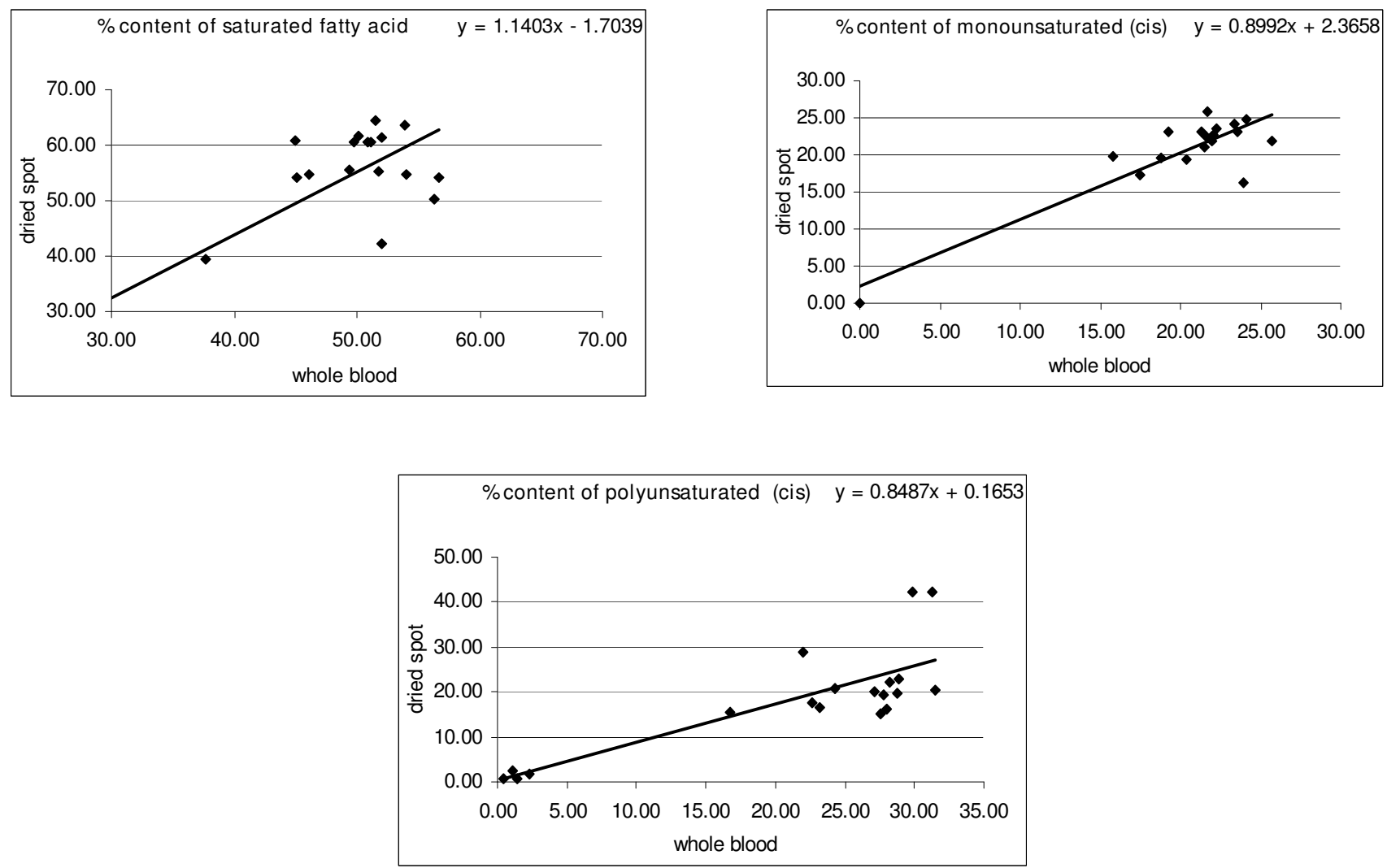

Figure I

Scatter-plot for saturated, mono unsaturated (cis) and poly unsaturated (cis) fatty acid extracted from whole blood and dried blood spot. Values are percentage of total fatty acids.
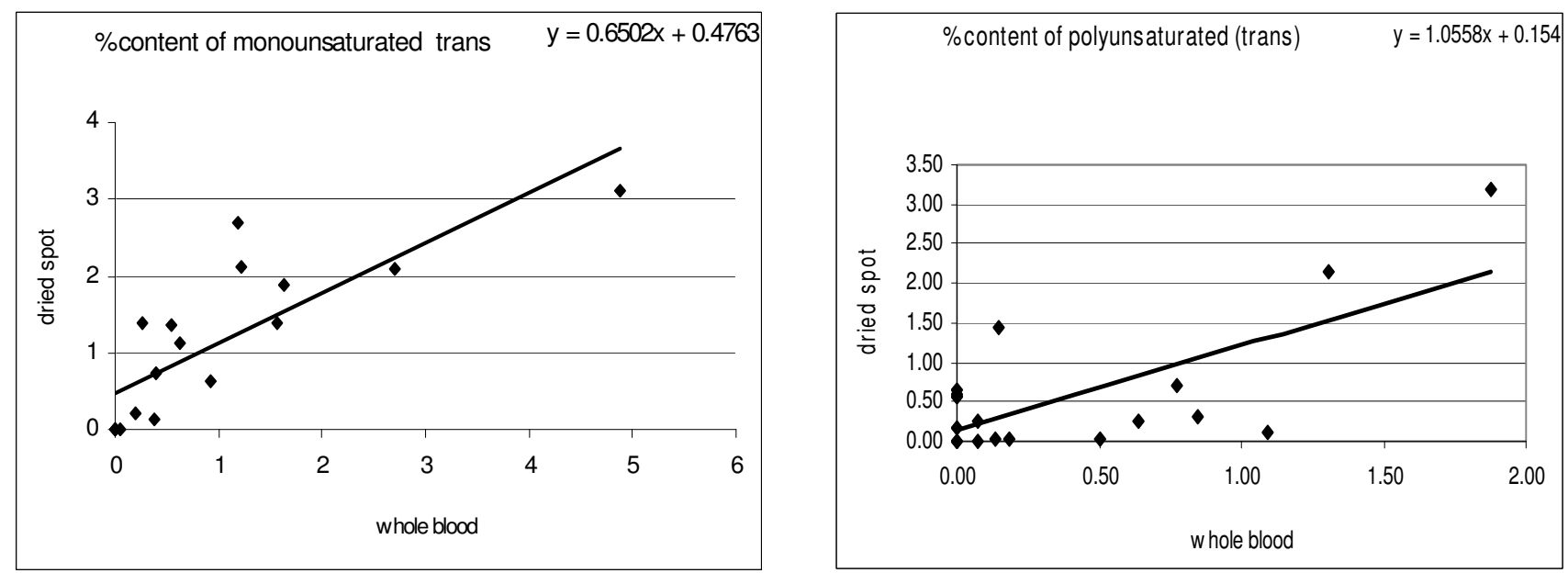

\section{Figure 2}

Scatter-plot for mono unsaturated (trans) and poly unsaturated (trans) fatty acid extracted from whole blood and dried blood spot. Values are percentage of total fatty acids. 
Table I: Correlation between fatty acids extracted from whole blood and dried blood spots $(\mathrm{n}=19)$

\begin{tabular}{lcc}
\hline & Pearson correlation coefficient ' $r$ ' & $\begin{array}{c}\text { Intraclass correlation coefficient } \\
(\mathbf{9 5 \%} \mathbf{C l})\end{array}$ \\
\hline Total saturated fatty acid & 0.827 & 0.880 \\
& & $(0.688-0.954)$ \\
\hline Total monounsaturated fatty acid (cis) & 0.883 & 0.937 \\
& & $(0.837-0.976)$ \\
\hline Total polyunsaturated fatty acid (cis) & 0.804 & $(0.715-0.957)$ \\
\hline Total monounsaturated fatty acid (trans) & & 0.890 \\
\hline Total polyunsaturated fatty acid (trans) & 0.701 & $(0.493-0.925)$ \\
\hline
\end{tabular}

samples as against dried blood samples. As is evident a good agreement was found between saturated, MUFA and PUFA values obtained with dried blood and whole blood. The correlations coefficient ( $r$ ) for trans MUFA and PUFA were 0.70 and 0.69 respectively. The trans fatty acid content was low in most of the samples. The Intraclass Correlation Coefficient for monounsaturated and polyunsaturated trans was 0.804 and 0.776 respectively, whereas for cis it was 0.890 and 0.937 respectively. The ICC for saturated fatty acid was 0.880 (Table 1 ).

\section{Discussion}

Fatty acid analysis from dried blood has been previously reported in the diagnosis of Adrenoleukodystrophy $[10,11]$. These studies did not look at stability of fatty acids in dried blood when compared with whole blood. The comparison of blood spot assay results with those from matched, simultaneously collected fresh samples through venipuncture is a validation tool to assess suitability of dried blood for analysis of specific analytes. The present study shows a good correlation between dried blood and fresh whole blood with correlation coefficients ranging from 0.70 to 0.88 (Figure $1 \& 2$ ).

The previously reported papers have also not looked at trans fatty acids in dried blood. Analysis of trans fatty acids has generated considerable interest in developing countries specially India where the prevalence of coronary artery disease is on the rise and the traditional risk factors are not able to explain the high rate of premature CAD in the country. Since the eating habits of Indian differ considerably from the Caucasians with consumption of more oil and fried food, trans fatty acid may be an important dietary contributing factor in predisposing Indians to CAD. Studies are needed in India to address this issue but the invasive nature of adipose tissue collection which is a gold standard for dietary fat intake is an obstacle in planning large population based studies. Blood may be an ideal choice but transportation of blood samples at very low temperatures to central laboratories for trans fatty acid estimation may be an issue. In this regard dried blood may be a viable alternative. In the present study we have demonstrated that trans fatty acids are stable in dried blood up to 15 days when stored at $4^{\circ} \mathrm{C}$. This will make transportation easier. In conclusion dried blood spots can be used for trans fatty acid analysis. Collection of blood spots eliminates the procedures of centrifugation and transportation of samples in dry-ice. This has an application in multicentric studies where large number of samples is involved.

\section{Abbreviations}

PUFA: Polyunsaturated fatty acid; MUFA: Monounsaturated fatty acid; ICC: Intraclass Correlation Coefficient.

\section{Competing interests}

The authors declare that they have no competing interests.

\section{Authors' contributions}

RL conceived the study design and wrote the manuscript, RG and SD carried out the work and KSR, DP \& RAA provided the intellectual input for manuscript preparation. All authors read and approved the final manuscript.

\section{References}

I. Sun Qi, Ma J, Campos H, Hankinson SE, Hu FB: Comparison between plasma and erythrocyte fatty acid content as biomarkers of fatty acid intake in US women. Am J Clin Nutr 2007, 86:74-8I.

2. Baylin $A, C a m p o s ~ H:$ The use of fatty acid biomarkers to reflect dietary intake. Curr Opin Lipidol 2006, 17:22-7. 
3. Baylin A, Kabagambe EK, Siles $X$, Campos $\mathrm{H}$ : Adipose tissue biomarkers of fatty acid intake. Am J Clin Nutr 2002, 76:750-757.

4. Baylin A, Kim MK, Donovan-Palmer A, Siles X, Dougherty, Tocco P, Campos $\mathrm{H}$ : Fasting whole blood as a biomarker of essential fatty acid intake in epidemiologic studies: Comparison with adipose tissue and plasma. American J Epidemiol 2005, 162:373-38I.

5. Lichtenstein $\mathrm{AH}$ : Trans fatty acids, plasma lipid levels and risk of developing cardiovascular disease. A statement for health care professional from American Heart Association. Circulation 1997, 95:2588-2590.

6. Lemaitre RN, King IB, Raghunathan TE, Pearce RM, Weimann S, Knopp RH, Copass MK, Cobb LA, Siscovick DS: Cell membrane trans fatty acid and risk of primary cardiac arrest. Circulation 2002, I05:697-70I.

7. Wilson TA, Mclntyre M, Nicolosi RJ: Trans fatty acids and cardiovascular risk. J Nutr Health Aging 200I, 5(3): I84-187.

8. Rose HG, Oklander M: Improved procedure for the extraction of lipids from human erythrocytes. J lipid Res 1965, 6:428-43I.

9. Leepage G, Roy CC: Direct transesterification of all classes of lipids in a one-step reaction. J Lipid Res 1986, 27: I I4-120.

10. Ishikawa Y, Minami R, Nakao T: Diagnosis of Adrenoleukodystrophy using dried blood spot. The Tohoku J of Experimental Medicine 1985, I 46(I):69-72.

II. Inoue K, Suzuki Y, Yajima S, Shimozawa N, Orii T, Kondo N: Very long chain fatty acid analysis of dried blood spots on filter paper to screen for Adrenoleukodystrophy. Clin Chem 1997, 43:2197-2198.

Publish with Bio Med Central and every scientist can read your work free of charge

"BioMed Central will be the most significant development for disseminating the results of biomedical research in our lifetime. "

Sir Paul Nurse, Cancer Research UK

Your research papers will be:

- available free of charge to the entire biomedical community

- peer reviewed and published immediately upon acceptance

- cited in PubMed and archived on PubMed Central

- yours - you keep the copyright

Submit your manuscript here:

http://www.biomedcentral.com/info/publishing_adv.asp
BioMedcentral 